\title{
Three-dimensional ankle kinematics in children's school shoes during running
}

\author{
Caleb Wegener ${ }^{1 *}$, Damien O'Meara², Adrienne E Hunt ${ }^{1}$, Joshua Burns ${ }^{3}$, Benedicte Vanwanseele ${ }^{4}$, Andrew Greene $^{1}$, \\ Richard M Smith
}

From 3rd Congress of the International Foot and Ankle Biomechanics Community

Sydney, Australia. 11-13 April 2012

\section{Background}

Children are more active during the school day than at other times [1] and because school shoes are required as part of a uniform in many countries research on school shoes is required. This study aimed to determine the effect of school shoes on the ankle joint complex motion of children while running.

\section{Materials and methods}

Twenty children (mean age 9 years (SD2.3)) performed five running trials at a self-selected velocity barefoot and wearing school shoes (Daytona, Clarks) in a random order. A 14 camera $200 \mathrm{~Hz}$ motion analysis system (EVaRT5.0, MAC) was used to calculate marker trajectories. Markers were attached to the right leg and a cluster wand was attached to the calcaneus through a window in the shoe. A standing reference trial was used to embed segment axes and then calculate ankle joint complex motion. Force plate data were collected at $1000 \mathrm{~Hz}$ (Kistler ${ }^{\mathrm{TM}}$ ). Data were normalised to the stance phase and sub-phases partitioned from the anterior/posterior force data as: loading (initial-contact - maximumnegative force); mid-stance (maximum-negative force zero) and propulsion (positive force - toe-off).

\section{Results}

Shoes delayed the maximum-posterior force $(22.8 \%$ to 29.3\%; $p<0.0001)$ and the zero crossing of the anteriorposterior force $(41.1 \%$ to $43.6 \% ; p=0.021)$. During loading shoes increased ankle range of motion (ROM) in the sagittal $\left(9.9^{\circ}\right.$ to $\left.13.8^{\circ} ; p=0.007\right)$ and transverse planes $\left(5.7^{\circ}\right.$ to $\left.7.7^{\circ} ; p=0.007\right)$. During midstance shoes decreased ankle frontal plane $\mathrm{ROM}\left(3.7^{\circ}\right.$ to $2.8^{\circ}$; $p=0.037)$. During propulsion shoes increased ankle ROM in the sagittal plan $\left(30.3^{\circ}\right.$ to $\left.33.3^{\circ} ; p=0.018\right)$ and decreased frontal plane ROM $\left(14.4^{\circ}\right.$ to $\left.12.0^{\circ} ; p=0.042\right)$. Overall stance phase sagittal plane ROM increased in shoes $\left(31.2^{\circ}\right.$ to $\left.34.2^{\circ} ; p=0.034\right)$.

\section{Conclusions}

This study shows that school shoes increase sagittal ankle motion during loading and propulsion, but decrease frontal plane motion during mid-stance and propulsion. These findings will assist in harmonising school shoe design with foot function.

\section{Author details}

${ }^{1}$ Discipline of Exercise and Sports Science, Faculty of Health Sciences, The University of Sydney, NSW, 1825, Australia. ${ }^{2}$ New South Wales Institute of Sport, Sydney, NSW, 2129, Australia. ${ }^{3}$ Faculty of Health Sciences, The University of Sydney / Institute for Neuroscience and Muscle Research, The Children's Hospital at Westmead, Sydney, NSW, 2145, Australia. ${ }^{4}$ Research Centre for Exercise and Health, KULeuven, Leuven, Belgium / Chair Health Innovation and Technology, Fontys University of Applied Sciences, Eindhoven, Netherlands.

Published: 10 April 2012

\section{Reference}

1. Page A, Cooper AR, Stamatakis E, Foster L, Crowne EC, Sabin M, Shield JP: Physical activity patterns in nonobese and obese children assessed using minute-by-minute accelerometry. Int J Obes (Lond) 2005, 29:1070-1076

doi:10.1186/1757-1146-5-S1-020

Cite this article as: Wegener et al: Three-dimensional ankle kinematics in children's school shoes during running. Journal of Foot and Ankle Research 2012 5(Suppl 1):O20.

\footnotetext{
* Correspondence: cweg6974@uni.sydney.edu.au

'Discipline of Exercise and Sports Science, Faculty of Health Sciences, The University of Sydney, NSW, 1825, Australia

Full list of author information is available at the end of the article
} 